CrossMark

\&click for updates

Cite this: Dalton Trans., 2015, 44 19059

Received 11th September 2015, Accepted 7th October 2015

DOI: 10.1039/c5dt03559g

www.rsc.org/dalton

\section{A versatile and highly efficient post-functionalization method for grafting organic molecules onto Anderson-type polyoxometalates $\uparrow$}

\author{
Stef Vanhaecht, Jeroen Jacobs, Luc Van Meervelt and Tatjana N. Parac-Vogt*
}

\begin{abstract}
A new azide functionalized Anderson polyoxometalate was synthesized, fully characterized and subsequently used as a building block for further POM post-functionalization with organic compounds through a copper catalyzed azide-alkyne cycloaddition (CuAAC) reaction. Optimization of the reaction conditions led to an efficient, fast, convenient and versatile POM coupling method.
\end{abstract}

Polyoxometalates (POMs) form a diverse class of metal-oxygen clusters characterized by versatile physical and chemical properties. Their diversity in terms of structure, polarity, charge density and redox-behavior make them attractive compounds in numerous applications, including the development of new materials, ${ }^{1}$ catalysis ${ }^{2}$ and the use for medicinal purposes. ${ }^{3}$ The functionalization of POMs with organic groups to create an organic-inorganic hybrid POM has received much attention over the last few decades as it opens the door to the incorporation of POMs in larger chemical structures with distinct properties. $^{4}$

An important member of the hybrid POM family is the Mn(III) containing Anderson-type hybrid POM which was first reported in $2002 .^{5}$ Since its first publication, this type of POM has been widely used as a building block for further functionalization with organic groups, giving rise to hybrid POMs with ever growing complexity. The first synthetic approach for the formation of Anderson based hybrids is based on direct functionalization, where a trisalkoxo functionalized ligand is reacted with the tetrabutylammonium salt of $\left[\mathrm{Mo}_{8} \mathrm{O}_{26}\right]^{4-}$ as a precursor. ${ }^{6}$ A second approach relies on postfunctionalization, where a preformed hybrid POM containing a specific reactive group in its organic part reacts with the ligand of interest. ${ }^{7}$ However, the development of methods for

Department of Chemistry, KU Leuven, Celestijnenlaan 200F - bus 2404, 3001 Leuven, Belgium. E-mail: tatjana.vogt@chem.kuleuven.be

$\dagger$ Electronic supplementary information (ESI) available: Experimental details, ${ }^{1} \mathrm{H}$ and ${ }^{13} \mathrm{C}$ NMR spectra for compounds $\mathbf{1 - 4 e},{ }^{1} \mathrm{H}^{-13} \mathrm{C}$ HSQC NMR spectra for compounds 1 and 4a, FTIR data for compounds 2-4e, elemental analysis for compounds 1-4e and crystallographic data for compound 3. CCDC 1401599. For ESI and crystallographic data in CIF or other electronic format see DOI: 10.1039/ c5dt03559g this post-functionalization approach is a challenging task as suitable reaction conditions need to be found that take into account the delicate nature of the hybrid POM. ${ }^{4 c}$ In the literature several examples can be found on the post-functionalization of the Anderson hybrid POM based on amidation, ${ }^{7 c-f, h, i}$ imine formation ${ }^{7 a, b}$ or a Diels-Alder reaction. ${ }^{7 g}$ While these methods have proven their efficiency, these post-functionalization approaches often require long reaction times and need elevated temperatures to be efficient.

In this paper we investigate the use of copper(I)-catalyzed azide-alkyne cycloaddition (CuAAC) chemistry as a postfunctionalization method for the Anderson hybrid POM. The huge success of this reaction in organic chemistry relies on its selective nature, fast reaction kinetics and high yields, the absence of side-reactions, widely applicable substrates and reaction conditions and the formation of a stable 1,2,3-triazole bond which is insensitive towards hydrolysis or redox reactions. ${ }^{8}$ Moreover, as the reaction is unaffected by any other functional groups present in the substrate, potentially harmful protection/deprotection reactions can be avoided in the presence of the hybrid POM. Very recently, Cronin et al. have demonstrated a fascinating control over the formation of nanosized metal oxide oligomers of hybrid polyoxometalates with the help of a click reaction. ${ }^{9}$ In that approach $\mathrm{CuI}$ was used as a catalyst as the classic $\mathrm{Cu}(\mathrm{II}) \mathrm{SO}_{4} /$ sodium ascorbate system seemed inapplicable due to the formation of reduced POMclusters.

Here we describe the development of robust CuAAC methods to covalently graft a range of organic molecules onto a novel azide-functionalized Anderson POM, under very mild reaction conditions. We developed a new approach in which both $\mathrm{Cu}$ (I) and $\mathrm{Cu}$ (II) can be used as catalysts giving high yields in very short reaction times, making this CuAAC-based coupling system a very attractive method in the development of more complex hybrid POM structures.

The synthesis of the double azide-functionalized Anderson hybrid POM (compound 3) is straightforward, starting from cheap and easily obtained starting materials, and could easily be scaled up without any loss of yield or purity (synthetic 
procedures and characterization in the ESI $\dagger$ ). Its single crystal $\mathrm{X}$-ray structure shows 4 equivalents of hybrid POM structures in the asymmetric unit, together with 12 tetrabutylammonium (TBA) counterions, ten acetonitriles and a half ethanol molecule.t The molecular structure of one POM entity is shown in Fig. 1.

In order to investigate the ability of compound 3 to be used for azide-alkyne cycloadditions, different reaction conditions were examined, keeping in mind the various limitations imposed by the fragility of the POM framework. Ion pairing between negatively charged Keggin and Wells-Dawson POMs and copper ions in solution has already shown to lower the concentration of active catalyst in solution, hence the necessity of using high copper concentrations when applying these catalytic systems. ${ }^{10}$ Two types of $\mathrm{Cu}(\mathrm{I})$ catalytic systems were explored, a preformed air-stable $\mathrm{Cu}(\mathrm{I})$ catalyst, namely $\mathrm{Cu}(\mathrm{I})\left(\mathrm{CH}_{3} \mathrm{CN}\right)_{4} \mathrm{PF}_{6}$, and the classic $\mathrm{CuSO}_{4} /$ sodium ascorbate approach, where the active $\mathrm{Cu}(\mathrm{I})$ species are formed in situ by reduction of $\mathrm{Cu}$ (II) to $\mathrm{Cu}(\mathrm{I})$ by sodium ascorbate. In the case of the $\mathrm{Cu}(\mathrm{I})\left(\mathrm{CH}_{3} \mathrm{CN}\right)_{4} \mathrm{PF}_{6}$ system (method A) reactions were performed in acetonitrile, which is known to protect the $\mathrm{Cu}(\mathrm{I})$ ion against oxidation by any residual oxygen in the reaction mixture. The initial reactions were performed using phenylacetylene as an alkyne-substrate, 1 equivalent of $\mathrm{N}, \mathrm{N}$-diisopropylethylamine (DIPEA) as an organic base and 1 equivalent of $\mathrm{Cu}(\mathrm{I})\left(\mathrm{CH}_{3} \mathrm{CN}\right)_{4} \mathrm{PF}_{6}$ to counter the loss of $\mathrm{Cu}(\mathrm{I})$ catalyst

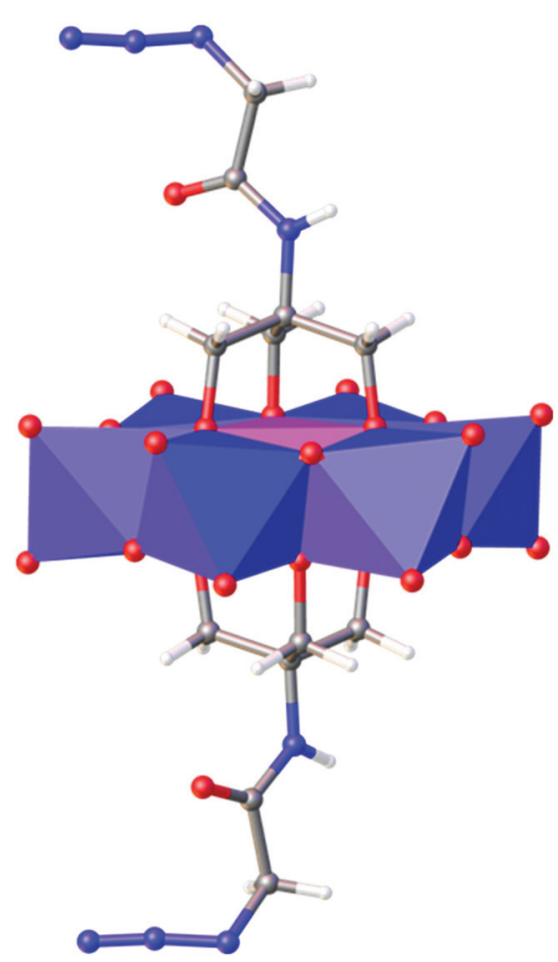

Fig. 1 Molecular structure of compound 3. Only one of the four equivalent POMs is shown. Tetrabutylammonium counterions were omitted for clarity (blue octahedra: Mo, pink octahedron: Mn, grey: C, red: $O$, blue: $\mathrm{N}$, white: $\mathrm{H}$ ). through ion pairing to the negatively charged POM. The addition of DIPEA to the reaction mixture resulted in the immediate formation of a yellow precipitate. The precipitation was presumably attributed to the formation of an insoluble $\mathrm{Cu}(\mathrm{I})$-acetylide complex, which was also formed in the absence of the POM. ${ }^{8}$ The reaction was followed by FTIR spectroscopy, where the disappearance of the azide peak at $2105 \mathrm{~cm}^{-1}$ was a clear indication of the course of the reaction. Despite the heterogeneous nature of the reaction mixture, the reaction reached completion after 75 minutes at $70{ }^{\circ} \mathrm{C}$. In addition to the $\mathrm{Cu}(\mathrm{I})$-acetylide complex, a different precipitate formed, which was attributed to the ion-pairing of the POM with the copper ions in solutions. Both precipitates redissolved after treatment with a $\mathrm{TBA}^{+}$-loaded resin. The compound was isolated in high yield and characterized by FTIR, ${ }^{1} \mathrm{H}$ and ${ }^{13} \mathrm{C}$ NMR spectroscopy. The existence of the formed triazole ring was proven by the typical ${ }^{1} \mathrm{H}$ signal at $8.54 \mathrm{ppm}$ and two ${ }^{13} \mathrm{C}$ signals at 123 and $146 \mathrm{ppm}$. Performing the reaction at room temperature led to prolonged reaction times (48-72 h), pointing towards the need for elevated temperatures, presumably to overcome the heterogeneous nature of the reaction conditions. Decreasing the copper content to 0.5 equivalent led to slightly slower reactions $(3 \mathrm{~h})$, but the reaction benefits from the lower amount of precipitation, clearly speeding up the ion-exchange step. The crucial role of the base was demonstrated as in its absence no reaction occurred, even after 2 days of reaction.

The second copper source which was examined in this study was the $\mathrm{CuSO}_{4} /$ sodium ascorbate approach (method B) in combination with DMF as a solvent. Using phenylacetylene, 1 equivalent of $\mathrm{CuSO}_{4} \cdot 5 \mathrm{H}_{2} \mathrm{O}$ and 2 equivalents of sodium ascorbate, the coupling reaction reached completion after only 10 minutes at room temperature, after which a consecutive work-up similar to that of method A could be performed. In contrast to previous reports in the literature, no sign of any reduced Mo-POM species, characterized by a typical blue color, was observed. ${ }^{9}$ Presumably the order of addition and the initial low solubility of sodium ascorbate in the reaction mixture prevent POM reduction, rendering this method applicable for molybdenum containing POM systems. In order to optimize the reaction conditions of the CuAAC reaction, experiments were performed by using lower copper contents. Using $0.1 \mathrm{eq}$. of the copper source, the reaction proceeded for $c a$. one hour, after which progress stopped. This was accompanied by the formation of a small amount of precipitate, which most likely resulted in the decrease of $\mathrm{Cu}(\mathrm{I})$ concentration, which is an active catalyst for the reaction. Increasing the catalyst concentration to 0.5 equivalent proved beneficial, as the reaction was homogeneous and nearly completed in only 15 minutes. The results of the different reactions are summarized in Table 1.

After having established efficient reaction conditions for the grafting of phenylacetylene onto compound 3, several other substrates were used to demonstrate the wide applicability of the CuAAC reaction on this POM. Method B was chosen, as it had already proved to be very fast, requiring a 
Table 1 Coupling of phenylacetylene to compound 3 using different reaction conditions in a CuAC coupling reaction

\begin{tabular}{lllllll}
\hline & & & & \\
& & & Acetonitrile (Method A) \\
Reaction conditions \\
see table
\end{tabular}

${ }^{a}$ No reaction occurred after $48 \mathrm{~h}$, and DIPEA needed to initialize the reaction. ${ }^{b}$ Reaction proceeded for about 1 hour, after which progress stalled.

minimal work-up and giving desired products in high yields. Next to the aromatic alkyne phenylacetylene, an $\alpha$-carbonyl alkyne (ethyl propiolate) and three alkyl alkynes (4-bromo-1butyne, 1-hexyne and 3-butyn-1-ol) were used as a substrate in the coupling reaction (see Chart 1). After 1 hour of reaction, the FTIR spectrum showed that all substrates were efficiently coupled to compound 3 in high yields. After the work-up all grafted POMs were characterized by FTIR, ${ }^{1} \mathrm{H}$ and ${ }^{13} \mathrm{C}$ NMR spectroscopy. The results of these coupling reactions are summarized in Table 2.

In conclusion, we have demonstrated the preparation of a novel azide-functionalized Anderson polyoxometalate and its potential as a platform for grafting organic molecules onto the POM surface via the CuAAC reaction. A reliable and efficient coupling method was established, characterized by very short reaction times, mild conditions and ease of work-up, affording the desired functionalized polyoxometalates in high yields and purities. The method also does not cause reduction of POM species, rendering it applicable for other molybdenum containing POM systems. Due to all these advantages, the method presented in this paper has potential to become the postfunctionalization reaction of choice for the formation of organic/inorganic hybrids involving Anderson POM, leading to

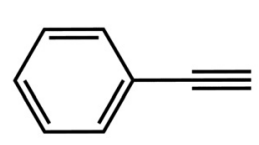

Phenylacetylene

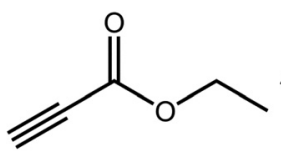

Ethyl propiolate

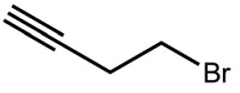

4-bromo-1-butyne

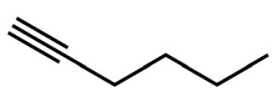

1-hexyne

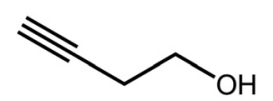

3-butyn-1-ol
Chart 1 Alkyne-substrates used for grafting onto compound 3.
Table 2 Coupling of different alkyne-substrates to compound 3

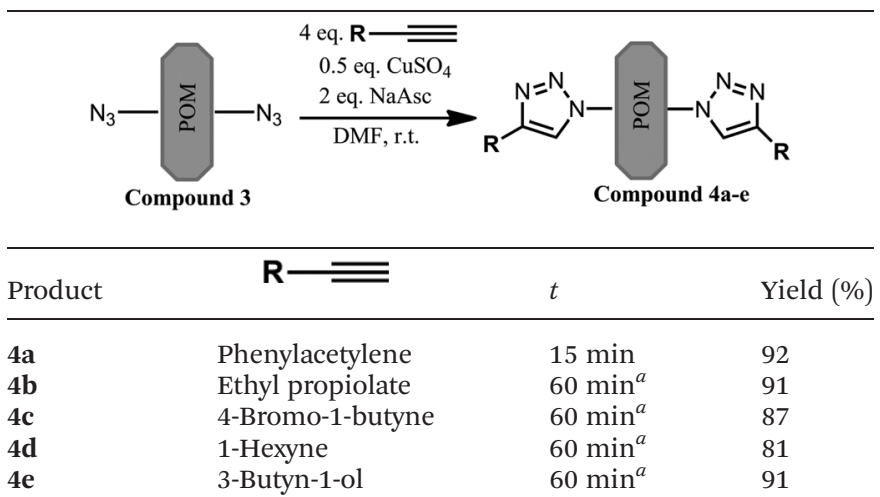

${ }^{a}$ FTIR spectra were taken after 60 min of reaction.

a large range of novel functionalized POMs for various applications.

T. N. P.-V. thanks KU Leuven and FWO Flanders for financial support. S. V. acknowledges the 'Agency for Innovation by Science and Technology in Flanders' (IWT) for a doctoral fellowship. J. J. and L. V. M. thank the Hercules Foundation for supporting the purchase of the diffractometer through project AKUL/09/0035.

\section{Notes and references}

$\ddagger \mathrm{C}_{259.62} \mathrm{H}_{531.23} \mathrm{Mn}_{4} \mathrm{Mo}_{24} \mathrm{~N}_{54} \mathrm{O}_{104.50}, M=8604.29 \mathrm{~g} \mathrm{~mol}^{-1}$, triclinic, $P \overline{1}$ (no. 2), $a=$ 22.0899(3) $\AA, b=29.6893(4) \AA, c=31.1610(5) \AA, \alpha=112.9562(15)^{\circ}, \beta=91.6469$ $(13)^{\circ}, \gamma=102.4493(12)^{\circ}, V=18230.3(5) \AA^{3}, T=100.01(10) \mathrm{K}, Z=2, \rho_{\text {calcd }}=1.567 \mathrm{~g}$ $\mathrm{cm}^{-3}, \mu($ Mo K $\alpha)=1.008 \mathrm{~mm}^{-1}, F(000)=8822$, crystal size $0.4 \times 0.2 \times 0.2 \mathrm{~mm}^{3}$, 133565 reflections measured, 66545 unique $\left(R_{\text {int }}=0.0401\right)$ which were used in all calculations, 4208 parameters, 4105 restraints. The final $w R_{2}$ was 0.1918 (all data) and $R_{1}$ was $0.0895(I \geq 2 \operatorname{sigma}(I))$. 
1 (a) D.-L. Long, E. Burkholder and L. Cronin, Chem. Soc. Rev., 2007, 36, 105-121; (b) D. L. Long, R. Tsunashima and L. Cronin, Angew. Chem., Int. Ed., 2010, 49, 1736-1758.

2 H. Lv, Y. V. Geletii, C. Zhao, J. W. Vickers, G. Zhu, Z. Luo, J. Song, T. Lian, D. G. Musaev and C. L. Hill, Chem. Soc. Rev., 2012, 41, 7572.

3 J. T. Rhule, C. L. Hill and D. A. Judd, Chem. Rev., 1998, 98, 327-357.

4 (a) A. Proust, R. Thouvenot and P. Gouzerh, Chem. Commun., 2008, 1837-1852; (b) A. Dolbecq, E. Dumas, C. R. Mayer and P. Mialane, Chem. Rev., 2010, 110, 60096048; (c) A. Proust, B. Matt, R. Villanneau, G. Guillemot, P. Gouzerh and G. Izzet, Chem. Soc. Rev., 2012, 41, 7605.

5 B. Hasenknopf, R. Delmont, P. Herson and P. Gouzerh, Eur. J. Inorg. Chem., 2002, 1081-1087.

6 (a) S. Favette, B. Hasenknopf, J. Vaissermann, P. Gouzerh and C. Roux, Chem. Commun., 2003, 2664-2665; (b) Y. F. Song, D. L. Long and L. Cronin, Angew. Chem., Int. Ed., 2007, 46, 3900-3904; (c) M. H. Rosnes, C. Musumeci, C. P. Pradeep, J. S. Mathieson, D. L. Long, Y. F. Song, B. Pignataro, R. Cogdell and L. Cronin, J. Am. Chem. Soc., 2010, 132, 15490-15492; (d) Y. Yan, H. Wang, B. Li, G. Hou, Z. Yin, L. Wu and V. W. W. Yam, Angew. Chem., Int. Ed., 2010, 49, 9233-9236; (e) M. H. Rosnes, C. Musumeci, C. Yvon, A. Macdonell, C. P. Pradeep, C. Sartorio, D. L. Long, B. Pignataro and L. Cronin, Small, 2013, 9, 2316-2324.

7 (a) P. R. Marcoux, B. Hasenknopf, J. Vaissermann and P. Gouzerh, Eur. J. Inorg. Chem., 2003, 2406-2412; (b) Y. F. Song, D. L. Long, S. E. Kelly and L. Cronin, Inorg. Chem., 2008, 47, 9137-9139; (c) Y. F. Song, N. McMillan, D. L. Long, J. Thiel, Y. Ding, H. Chen, N. Gadegaard and L. Cronin, Chem. - Eur. J., 2008, 14, 2349-2354; (d) Y. F. Song, N. McMillan, D. L. Long, S. Kane, J. Malm,
M. O. Riehle, C. P. Pradeep, N. Gadegaard and L. Cronin, J. Am. Chem. Soc., 2009, 131, 1340-1341; (e) Y. Wang, X. Wang, X. Zhang, N. Xia, B. Liu, J. Yang, W. Yu, M. Hu, M. Yang and W. Wang, Chem. - Eur. J., 2010, 16, 1254512548; $(f)$ M. Hutin, C. Yvon, J. Yan, A. Macdonell, D. L. Long and L. Cronin, CrystEngComm, 2013, 15, 44224430; $(g)$ H. K. Yang, M. M. Su, L. J. Ren, J. Tang, Y. K. Yan, W. K. Miao, P. Zheng and W. Wang, Eur. J. Inorg. Chem., 2013, 1381-1389; (h) C. Yvon, A. Macdonell, S. Buchwald, A. J. Surman, N. Follet, J. Alex, D.-L. Long and L. Cronin, Chem. Sci., 2013, 4, 3810; (i) C. Yvon, A. J. Surman, M. Hutin, J. Alex, B. O. Smith, D. L. Long and L. Cronin, Angew. Chem., Int. Ed., 2014, 53, 3336-3341.

8 M. Meldal and C. W. Tomøe, Chem. Rev., 2008, 108, 29523015.

9 A. Macdonell, N. A. B. Johnson, A. J. Surman and L. Cronin, J. Am. Chem. Soc., 2015, 137, 5662-5665.

10 (a) K. Micoine, B. Hasenknopf, S. Thorimbert, E. Lacôte and M. Malacria, Org. Lett., 2007, 9, 3981-3984; (b) A. Harriman, K. J. Elliott, M. a. H. Alamiry, L. L. Pieux, M. Séverac, Y. Pellegrin, E. Blart, C. Fosse, C. Cannizzo, C. R. Mayer and F. Odobel, J. Phys. Chem. C, 2009, 113, 5834-5842; (c) K. J. Elliott, A. Harriman, L. Le Pleux, Y. Pellegrin, E. Blart, C. R. Mayer and F. Odobel, Phys. Chem. Chem. Phys., 2009, 11, 8767-8773; (d) F. Odobel, M. Séverac, Y. Pellegrin, E. Blart, C. Fosse, C. Cannizzo, C. R. Mayer, K. J. Elliott and A. Harriman, Chem. - Eur. J., 2009, 15, 3130-3138; (e) M.-B. Hu, N. Xia, W. Yu, C. Ma, J. Tang, Z.-Y. Hou, P. Zheng and W. Wang, Polym. Chem., 2012, 3, 617-620; $(f)$ J. Lesage de la Haye, P. Beaunier, L. Ruhlmann, B. Hasenknopf, E. Lacôte and J. Rieger, ChemPlusChem, 2014, 79, 250-256; $(g)$ A. M. Debela, M. Ortiz, C. K. Osullivan, S. Thorimbert and B. Hasenknopf, Polyhedron, 2014, 68, 131-137. 